\title{
BMJ Open Access to maternal healthcare services among Indigenous women in the Chittagong Hill Tracts, Bangladesh: A cross-sectional study
}

Shahinoor Akter (D) , ${ }^{1,2,3,4}$ Jane Louise Rich, ${ }^{1,5}$ Kate Davies, ${ }^{6}$ Kerry Jill Inder (1) ${ }^{2,3,7}$

To cite: Akter S, Rich JL, Davies K, et al. Access to maternal healthcare services among Indigenous women in the Chittagong Hill Tracts, Bangladesh: A crosssectional study. BMJ Open 2019;9:e033224. doi:10.1136/ bmjopen-2019-033224

- Prepublication history and additional material for this paper are available online. To view these files, please visit the journal online (http://dx.doi org/10.1136/bmjopen-2019033224).

Received 26 July 2019 Revised 05 September 2019 Accepted 25 September 2019

Check for updates

(C) Author(s) (or their employer(s)) 2019. Re-use permitted under CC BY-NC. No commercial re-use. See rights and permissions. Published by BMJ.

For numbered affiliations see end of article.

Correspondence to

Ms Shahinoor Akter

Shahinoor.Akter@uon.edu.au

\section{ABSTRACT}

Objectives This study aimed to estimate the prevalence of, and factors associated with, accessing maternal healthcare services (MHC) by Indigenous women in the Chittagong Hill Tracts (CHT), Bangladesh.

Design This was a cross-sectional survey among Indigenous women of reproductive age.

Setting Two upazillas (subdistricts) of Khagrachhari hill district of the CHT.

Participants Indigenous women (15-49 years) within 36 months of delivery were surveyed about accessing MHC services (antenatal care, delivery and postnatal care) for their last pregnancy and delivery.

Primary outcome measures The primary outcome for this analysis is the prevalence of accessing any MHC service and secondary outcome is factors associated with access to MHC services for Indigenous women during their last pregnancy and childbirth.

Results Of 438 Indigenous women (220 Chakma, 100 Marma, 118 Tripura) who participated, $75 \%$ were aged 16-30 years. With an $89 \%$ response rate, a total of 258 $(59 \%)$ women reported accessing at least one MHC service (Chakma 51.6\%, Marma 28\%, Tripura 20.5\%; $p=<0.001$ ). Independent factors associated with accessing MHC after adjusting for clustering were attending secondary school and above (OR 2.4; 95\% Cl 1.2 to 4.9); knowledge about nearest health facilities $(\mathrm{OR} 3.8,95 \% \mathrm{Cl} 1.8$ to 7.8$)$ and knowledge of pregnancy-related complications (OR 3.0, $95 \% \mathrm{Cl} 1.5$ to 5.8 ).

Conclusion Findings suggest that the prevalence of accessing MHC services is lower among Indigenous women in the $\mathrm{CHT}$ compared with national average. $\mathrm{MHC}$ access may be improved through better education and awareness raising of local services.

\section{INTRODUCTION}

Access to maternal healthcare (MHC) services is a key determinant of maternal mortality. Since WHO set a Millennium Development Goal (MDG) in 2000 to reduce the maternal mortality ratio (MMR; goal 5), the world has seen a $45 \%$ decline in MMR. ${ }^{1}$ However, the target of a $75 \%$ decline by 2015 was not achieved. ${ }^{23} \mathrm{~A}$ significant increase in women accessing MHC services around the world during pregnancy and delivery is a key factor
Strengths and limitations of this study

- This is the first study to report prevalence and factors associated with accessing maternal healthcare services among Indigenous women from three dominant Indigenous communities of the Khagrachhari district, the major ethnic groups in the two other hill districts sharing similar sociocultural status.

- This cross-sectional study, where measurements from the population were obtained at a single time point, precludes temporal sequence and causal inference.

- Data collection was designed to reduce bias and increase generalisability by attempting to recruit all eligible Indigenous women in the para/village.

- Not using Indigenous languages for the survey may have led to some communication barriers as the questionnaire did not use Indigenous dialectic terms for pregnancy and delivery, which may have restricted opportunities for transferring the knowledge to participants to some extent.

contributing to this decline, despite access gaps within MHC facilities. ${ }^{3}{ }^{4}$ To minimise those gaps, WHO Sustainable Development Goals emphasise improving MHC facilities so that, regardless of sociocultural background, women can have equal and easy access to quality MHC services ensuring universal health coverage. ${ }^{56}$

Bangladesh achieved notable success in improving maternal health in the MDG era with a $40 \%$ reduction of MMR from $322(95 \%$ CI 259 to 391$)$ to 194 (95\%CI 149 to 238) deaths per 100000 live births. ${ }^{4}$ Improved access and attendance at MHC services are key factors attributed to this outstanding reduction. ${ }^{8}$ This outcome does not imply that the reduction was inclusive and equitable for women from all sociocultural backgrounds ${ }^{9}$; rather there is a lack of information regarding MHC accessibility for cultural minority groups including 
Indigenous women in the Chittagong Hill Tracts (CHT) of Bangladesh. ${ }^{10} 11$

The CHT consists of three hill districts-Bandarban, Khagrachhari and Rangamati-located in the southeastern part of Bangladesh, home to 11 Indigenous communities with distinctive cultural and ethnic identities compared with the mainstream Bengali community. ${ }^{12-14}$ Apart from geographical and sociocultural differences, this area has a long history of political tensions that ended with the signing of a peace accord between the Government of Bangladesh and the Indigenous communities in 1997. More than 20 years have passed since the Peace Accord was signed and limited research has been conducted on Indigenous women's health issues in Bangladesh. ${ }^{15}$

Due to inadequate investment and limited research in Indigenous women's health issues, Indigenous women have the worst health record in the country. ${ }^{10} 1116$ According to the United Nations Children's Fund (UNICEF), the percentage of low-birth weight newborn babies is highest in the CHT, which is closely associated with maternal health during pregnancy and delivery. ${ }^{11}{ }^{17}$ In 2014, the Human Development Research Centre undertook a survey on various interventions of the CHT Development Facility (CHTDF); a multisectoral capacity building and development programme implemented by the United Nations development agency (United Nations Development Programme (UNDP)-CHTDF) for all CHT inhabitants since 2003. ${ }^{12}$ Understanding of basic MHC services among Indigenous women was lower compared with their Bengali counterparts. ${ }^{12}$ Evaluation from two UNDP-CHTDF programme household surveys (2008 and 2013) reported increased MHC service utilisation among Indigenous and non-Indigenous women in the intervention areas. ${ }^{6}$

Research on Indigenous women's health is limited and mostly conducted by international development organisations. ${ }^{15} 18$ Findings from a cross-sectional and a mixed-method study among Indigenous Mru women in Bandarban Hill district, Bangladesh, indicated that cultural issues, distance, infrastructure and socioeconomic status were important determinants of accessing MHC services. ${ }^{19} 20$

Distance to services, language barriers and cost are key barriers for Indigenous women accessing existing MHC services. ${ }^{20-25}$ The top-down nature of health intervention programmes can make services culturally unfriendly for Indigenous women in lower and middle income countries, impacting their access to available services. ${ }^{26}$ However, drawing the same conclusion for CHT Indigenous women is difficult due to the sociopolitical context and insufficient evidence. This study aims to determine the prevalence of accessing MHC services and to identify factors associated with accessing MHC services among CHT Indigenous women in Bangladesh.

\section{METHOD}

\section{Study design and setting}

This cross-sectional study was conducted between September 2017 and February 2018 in two subdistricts
(Upazila) of Khagrachhari district, Bangladesh. Khagrachhari is bound on the north by India, south by Chittagong and Rangamati district and on the west by India and Chittagong district. ${ }^{12} 27$ The Khagrachhari district is hilly with a significant proportion of the land area under forest ${ }^{27}$ (see figure 1).

Three major Indigenous groups: Chakma, Marma and Tripura inhabit Khagrachhari district comprising 50\% (315167 out of 613 917) of the district population with distinctive cultural features compared with the majority Bengali community. ${ }^{28}$ These ethnic communities speak Bangla language in addition to their mother tongue. ${ }^{12}$

\section{Sampling}

Khagrachhari district was purposively selected as the study site based on available data on Indigenous communities, available primary healthcare service centres and access to different ethnic communities. ${ }^{12}$ Khagrachhari has 9 subdistricts, 38 unions and 1706 villages, known as paras (the smallest administrative unit in the district). Distinct Indigenous groups reside together in particular paras. On average, a para consists of 241 people and each household comprises 5.2 members. ${ }^{12}$ Two subdistricts (Khagrachari Sadar and Matiranga) were chosen based on available public and private healthcare facilities ${ }^{28} ; 246$ paras in Khagrachhari Sadar and 365 paras in Matiranga subdistrict. ${ }^{28}$ The survey was administered in 47 selected paras with a high proportion of Indigenous residents; 41 in Matiranga and 6 in Khagrachhari Sadar.

\section{Study participants and sample size}

Inclusion criteria

Indigenous women aged 15-49 years from the three ethnic communities in the Khagrachhari district, who resided in their paras for at least 6 months prior to the survey and were within 36 months post delivery, were eligible to participate. Delivery included normal delivery or caesarean delivery. The outcome of their last pregnancy could be a live birth, stillbirth or miscarriage.

\section{Exclusion criteria}

Non-Indigenous women living in the same paras with Indigenous people were excluded from participating in the survey. Indigenous women who did not have the capacity to give informed consent, and where the researcher did not have the capacity to communicate with the women, were also excluded.

Sample size was estimated using a formula for a single population proportion with the assumptions of $95 \% \mathrm{CI}$, $5 \%$ margin of error and an expected $35.2 \%$ prevalence of women giving birth in a health institution in the Chittagong Division. ${ }^{29}$ Based on a non-response rate of $20 \%$ and the distribution of the three ethnic populations, the survey required 438 Indigenous women: 220 Chakma, 100 Marma and 118 Tripura women.

\section{Outcome measures}

The primary outcome of interest was the prevalence of accessing any MHC service, a dichotomous variable 


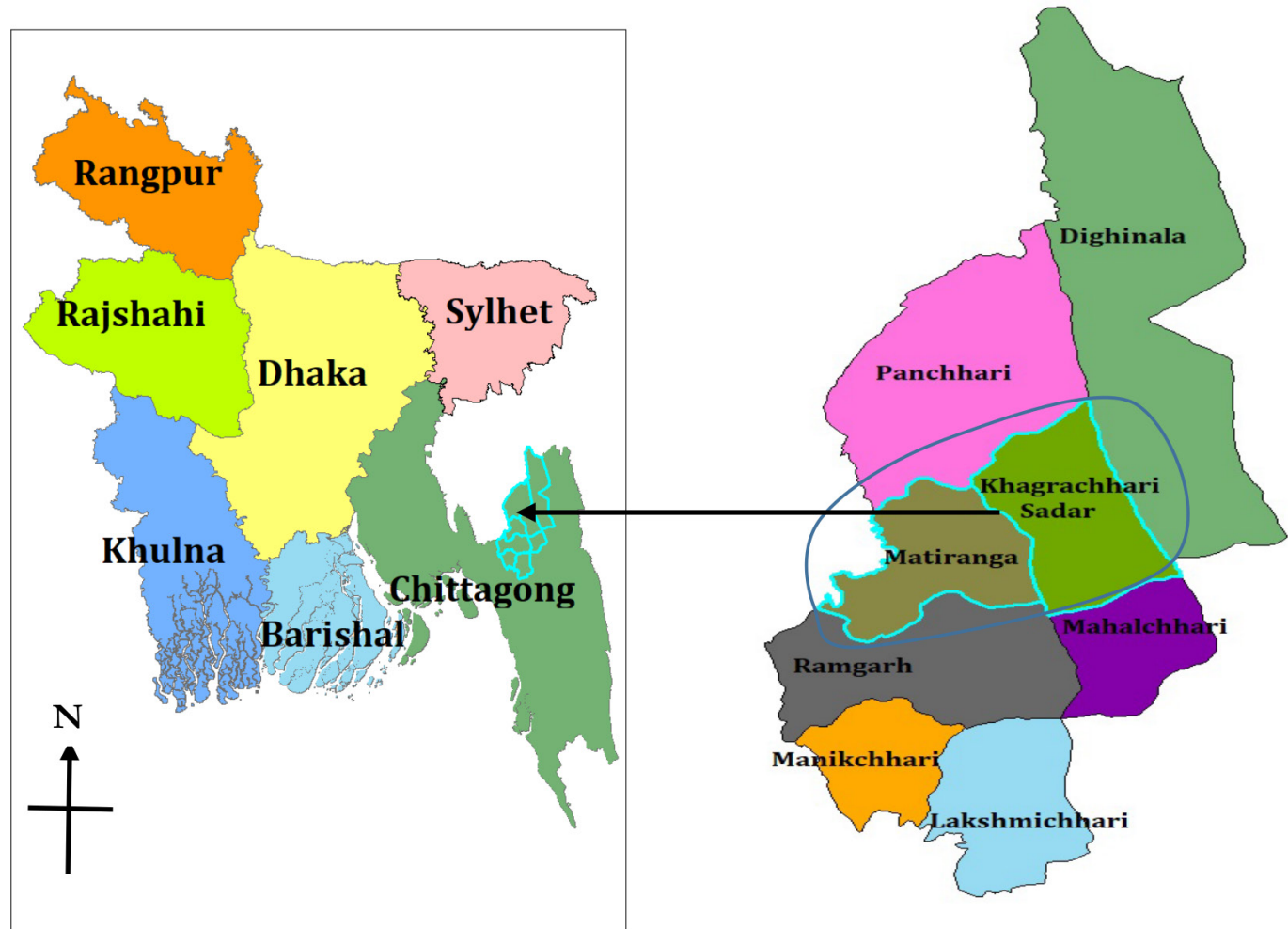

Figure 1 Map of Bangladesh and Khagrachhari district where the study was conducted (created using ArcMap V.10.6.1 software).

of accessing at least one MHC service (antenatal care (ANC), delivery or postnatal care (PNC)) from any primary healthcare facility or skilled community health worker during their last pregnancy or delivery or not. Prevalence was estimated by dividing the number of women within 36 months post delivery who reported accessing at least one MHC service during their last pregnancy or delivery, by the number of women within 36 months post delivery in the two subdistricts as informed by the Karbari. To reduce bias and increase generalisability of the findings, recruitment of all eligible Indigenous women in the para was attempted. Secondary outcomes were factors associated with attendance at any MHC service for Indigenous women during their last pregnancy and childbirth.

\section{Survey design}

The survey was modified based on two previous surveys. ${ }^{29} 30$ Information was collected on sociodemographic characteristics, reproductive history and knowledge and use of local services for women of reproductive age. Questions related to distance between home and MHC services facilities were asked and distance between the nearest health centres and each para was estimated using mobile global positioning system (GPS) applications. The survey was translated into English and Bangla by a local translator, and cross verified using independent speakers of Bangla and English.

\section{Data collection procedures}

Data were collected from participants by the first author (SA) and one field assistant from each of the three ethnic communities; all fluent in ethnic and Bengali languages. Field assistants underwent a 3-day training programme comprising the study objectives, survey conduct, cultural sensitivity, informed consent, privacy and confidentiality, use of survey software and survey field testing. REDCap software (Vanderbilt University, Nashville, Tennessee, USA), ${ }^{31}$ a web application for building and managing online surveys and databases, was used for data collection using tablet computers. To minimise unforeseeable situations, the survey team carried hard copies of the survey.

The survey was administered seeking verbal consent from participants as previous studies in CHT suggest that Indigenous people have trust issues with signed documents due to bitter experiences related to land acquisition practice. ${ }^{1932}$ Before accessing villages, the first author formally contacted the para karbari or headman (traditional community leader) to describe the study objectives and seek verbal permission to administer the survey. Prior to data collection, the research team visited local administrative offices to collect household lists and seek advice about the number of eligible Indigenous women in each household. Given the nature of Indigenous women's daily activities, community leaders suggested the best time to visit paras to approach women for interviews and provided a local guide to assist. Permission was sought from the head of the household if present and permission was sought from parents if the woman was aged under 18 years. The survey was conducted in Bangla. ${ }^{12}$ Three attempts were made to reach eligible women who were 
not at home; otherwise, those women were considered as 'missing'. Data were collected anonymously to ensure participants' confidentiality. Average duration of survey completion was $25 \mathrm{~min}$.

\section{Data analysis}

Software package STATA V.15 (StataCorp LLC, USA) was used to analyse data. All variables were checked for implausible values, errors and missing data. Associations between categorical variables were analysed using $\chi^{2}$ test and to assess factors associated with MHC services access within 3 years of delivery, univariate and multivariable logistic regression analyses were used. Factors of interest included demographic factors (age, ethnicity, religion, education, occupation, their partner's education and occupation, household income and subdistrict), reproductive history (age at first pregnancy, number of pregnancies, outcome of pregnancies, experience of pregnancy complications and expected number of children); knowledge about nearest health facilities, knowledge of pregnancy-related complications and access to media (see online supplementary table 1). Given small cell sizes, categories were collapsed to aid regression analysis for the variables of participants' and their partners' education status, and for participants' and partners' occupation. The variable 'number of pregnancies till survey date' was collapsed into two categories: '1-2 pregnancies' and ' 3 and above' reflecting the Bangladesh Population Policy that encouraged "No more than two children, but one is better' for all married couples. ${ }^{33}$ The variable 'knowledge of pregnancy-related complications' was categorised as 'mild, moderate (should see a doctor) or severe (needs immediate medical intervention)' using WHO and UNICEF recommendations. ${ }^{34}$

In the multivariable logistic regression model, variables with a $\mathrm{p} \leq 0.250$ on univariate analysis were included using a backward stepwise approach. Final model included variables with a $p<0.100$. As individual participants were nested within paras (primary sampling unit), and paras were nested within subdistricts, clustering by para was adjusted for in the model. Results are reported as OR, adjusted OR (AOR) and 95\% CIs.

\section{Partial patient and public involvement}

Respected members of Khagrachhari district community from the three Indigenous groups including school teachers, health professionals and non-government organisation officers were informed about the potential research to seek their support. These persons helped refine the research design and approach by providing important information regarding numbers of paras in the two field sites and the existence of health programme targeting Indigenous communities. Informed verbal consent was obtained from all participants prior to data collection. Participation was voluntary, and privacy and confidentiality were maintained.

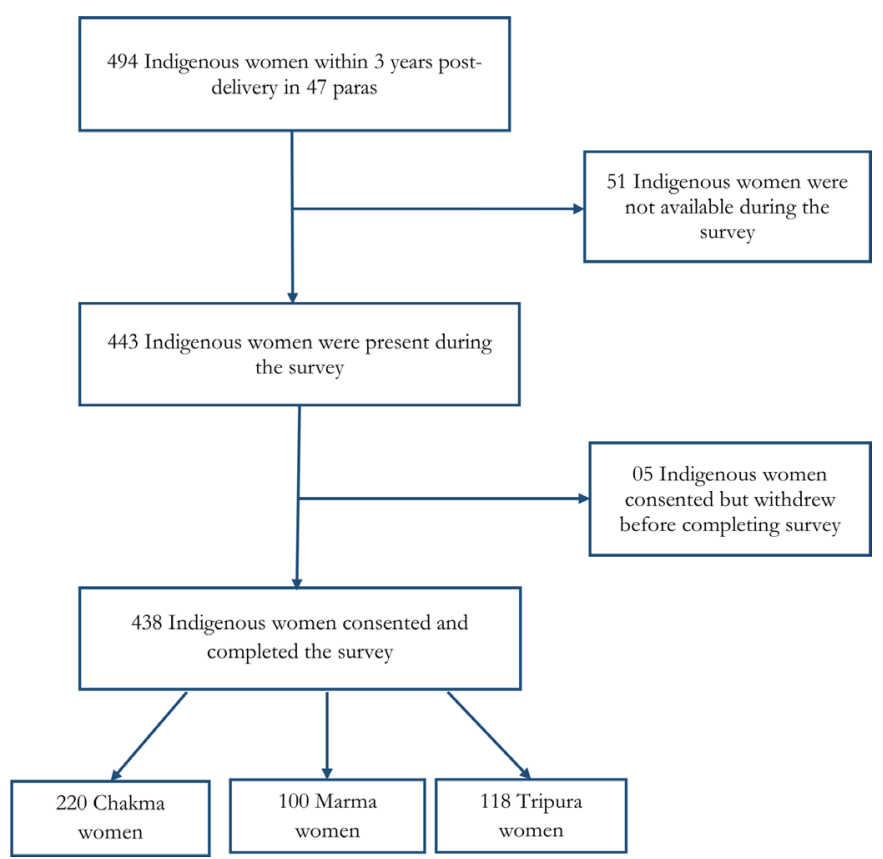

Figure 2 Flow chart defining the cohort of Indigenous women from Chittagong Hill Tracts, Bangladesh.

\section{RESULTS}

According to the health workers and community Karbari, 494 Indigenous women were permanent residents and living for the last 6 months in 47 paras in Matiranga (41 paras) and Khagrachhari sadar (6 paras) upazilas, having delivered at least one child, including miscarriage and abortion, within 3 years preceding the survey. Fifty-one Indigenous women $(11.3 \%)$ were not at home and documented as missing after three attempts to administer the survey. The remaining 443 women were invited to participate and 438 provided verbal consent; no participants were excluded. Five women who consented withdrew from the study before completing the survey. The overall response rate was $88.7 \%(438 / 494)$. Of the 438 women who completed the survey, $220(50.2 \%)$ were Chakma, 100 were Marma (22.8\%) and 118 (26.9\%) were Tripura women (see figure 2)

Of the 438 participants, $59 \%(n=258)$ accessed at least one MHC service related to their last pregnancy; the remaining $41 \%$ of participants $(n=180)$ did not report accessing any MHC services during their last pregnancy or delivery. Of the 258 participants who accessed at least one MHC service, $16 \% \quad(n=41)$ were aged between 13 and 19 years. Prevalence of accessing MHC services was $53 \%, 33 \%$ and $9.8 \%$ for ANC, delivery and PNC, respectively. Of the 258 participants who accessed at least one MHC service, $90 \%(\mathrm{n}=232)$ accessed ANC services, $16.7 \%(\mathrm{n}=43)$ accessed PNC services only and $6.4 \%$ $(n=28)$ accessed all three MHC services. Approximately, one quarter $(\mathrm{n}=115,26.3 \%)$ accessed ANC and delivery services, while only 23 women $(5.3 \%)$ reported accessing 


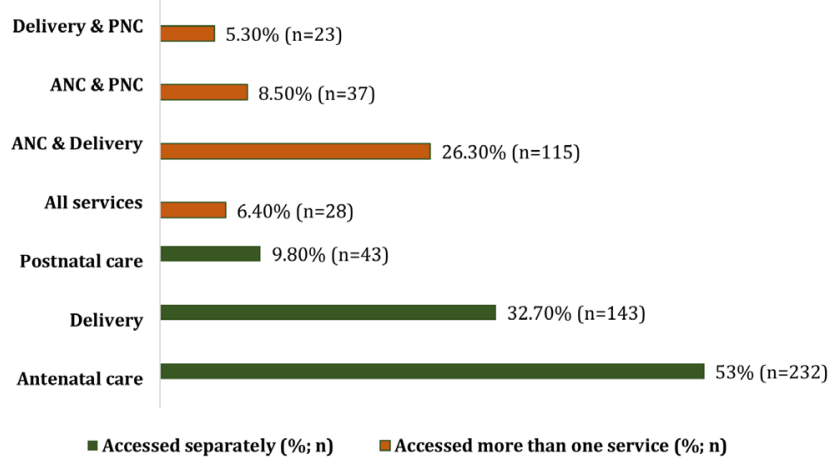

Figure 3 Estimated prevalence of accessing maternal healthcare services during pregnancy and delivery by the Indigenous women from Chittagong Hill Tracts, Bangladesh. ANC,- antenatal care; PNC,- postnatal care.

delivery and PNC services (see figure 3). Twenty-one participants $(15 \%)$ reported delivery of their last child by caesarean section.

Table 1 compares the demographic and obstetric characteristics of the CHT Indigenous women who accessed at least one MHC services within 36 months of delivery to those who did not access any MHC services. A significantly higher proportion of CHT Indigenous women who accessed MHC resided in Matiranga upazilla were older, had higher school attendance, were not involved in household income generating activities, had higher household income, had prior knowledge about nearest health facilities, did not access media for MHC information, had prior knowledge of pregnancy-related complications and experienced more pregnancy-related complications during the last pregnancy compared with those who did not access any MHC services. A significantly higher proportion of Indigenous women who did not access MHC services became pregnant before their $20^{\text {th }}$ birthday, experienced a negative pregnancy outcome (stillbirth/miscarriage/abortion) and had 2 deliveries in the last 3 years than women who did access MHC services.

Responses regarding distance to the nearest health facility was low. GPS data indicated that distance between the nearest health centres and each para ranged from 0.5 to $45 \mathrm{~km}$ with a mean (SD) distance of $12 \mathrm{~km}$ (13.4). Half of participants $(52.3 \%, \mathrm{n}=229)$ lived between 5 and $10 \mathrm{~km}$ from the nearest healthcare centre, with the closest centres more than $10 \mathrm{~km}$ away for $25.6 \%$ of participants. In many cases, there was no direct walkway or transport system to reach the facility due to the steep hilly landscape of the area.

In the multivariable logistic regression analysis, participants' age, ethnicity distance to facility, household income and access to media were not independent factors after adjusting for other variables in the model. Indigenous women who attended secondary school and above had twice the odds of accessing MHC services compared with Indigenous women who attended up to Junior school
(AOR 2.4, 95\% CI 1.2 to 4.9). Indigenous women with knowledge about nearest health clinics had nearly four times the odds of accessing MHC services (AOR 3.8, 95\% CI 1.8 to 7.8). Furthermore, Indigenous women with prior knowledge of pregnancy-related complications had three times the odds of accessing MHC services in comparison to Indigenous women who were unaware of complications (AOR 3.0, 95\% CI 1.5 to 5.8). Relative to Indigenous women with one or two parity, those with three and above had significantly reduced odds of accessing MHC services (AOR 0.54, 95\% CI 0.30 to 1.0; see table 2).

\section{DISCUSSION}

This landmark study in the CHT of Bangladesh included women from three different Indigenous groups to estimate prevalence and identify factors associated with access to MHC services. The proportion of participating Indigenous women from each group was representative of the ethnic distribution of the CHT population. ${ }^{28}$ Estimated prevalence of Indigenous CHT women accessing at least one MHC service for their last pregnancy was just over half (59\%) and for attending ANC services was 53\%; however, these rates differed among the three ethnic groups. The national average of women accessing any ANC service in Bangladesh according to 2014 Bangladesh Demographic and Health Survey report was $78 \%$ in $2014 .{ }^{29}$ Delivery at a healthcare facility was $37 \%$ with delivery by caesarean section $23 \% .{ }^{29}$ Among Indigenous women in the CHT, the percentage of accessing ANC and facility delivery services were $53 \%$ and $33 \%$, respectively, and $15 \%$ delivered their last child by caesarean section in the 3 years preceding the survey date. Key modifiable factors associated with attendance included education and knowledge about nearest health facilities and pregnancy-related complications.

Previously, research on MHC service utilisation by Indigenous women in the CHT reported low access to MHC services $(30.7 \%)^{19}$; however, results were not representative of the wider CHT Indigenous population as only one ethnic minority group was included. ${ }^{19}$ The Mru community is one of the most underprivileged ethnic minority groups in the CHT residing in remote and hilly areas of Bandarban district. ${ }^{19}$ Previous studies in lower and middle-income countries indicate distance to facilities and religion are associated with MHC access ${ }^{26}$; however, the current study did not find this. Minority groups, including Indigenous people, who experienced systematic discrimination, displacement or were undervalued by the majority groups might be reluctant or afraid of accessing health facilities. ${ }^{6} 2635$

Survey data from the UNDP-CHTDF intervention programme among Indigenous and non-Indigenous women in the CHT reported that ANC and facility delivery utilisation increased (by $18 \%$ and $23 \%$, respectively) among Indigenous women in the intervention areas however in women with experience of violence, 
Table 1 Sociodemographic characteristics of Indigenous women from Chittagong Hill Tracts, Bangladesh, who accessed at least one maternal healthcare service $(\mathrm{MHC})$ for last delivery

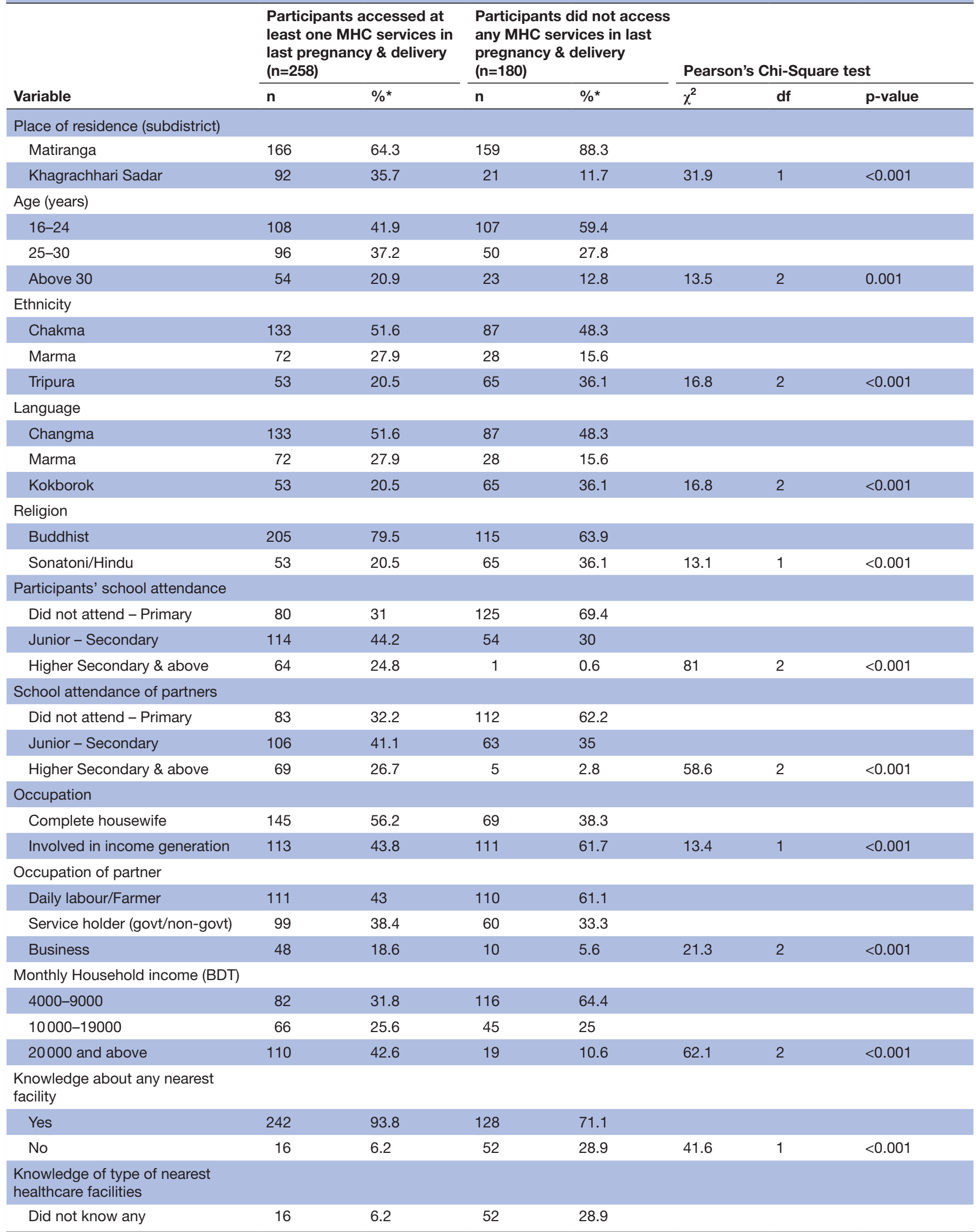

Continued 
Table 1 Continued

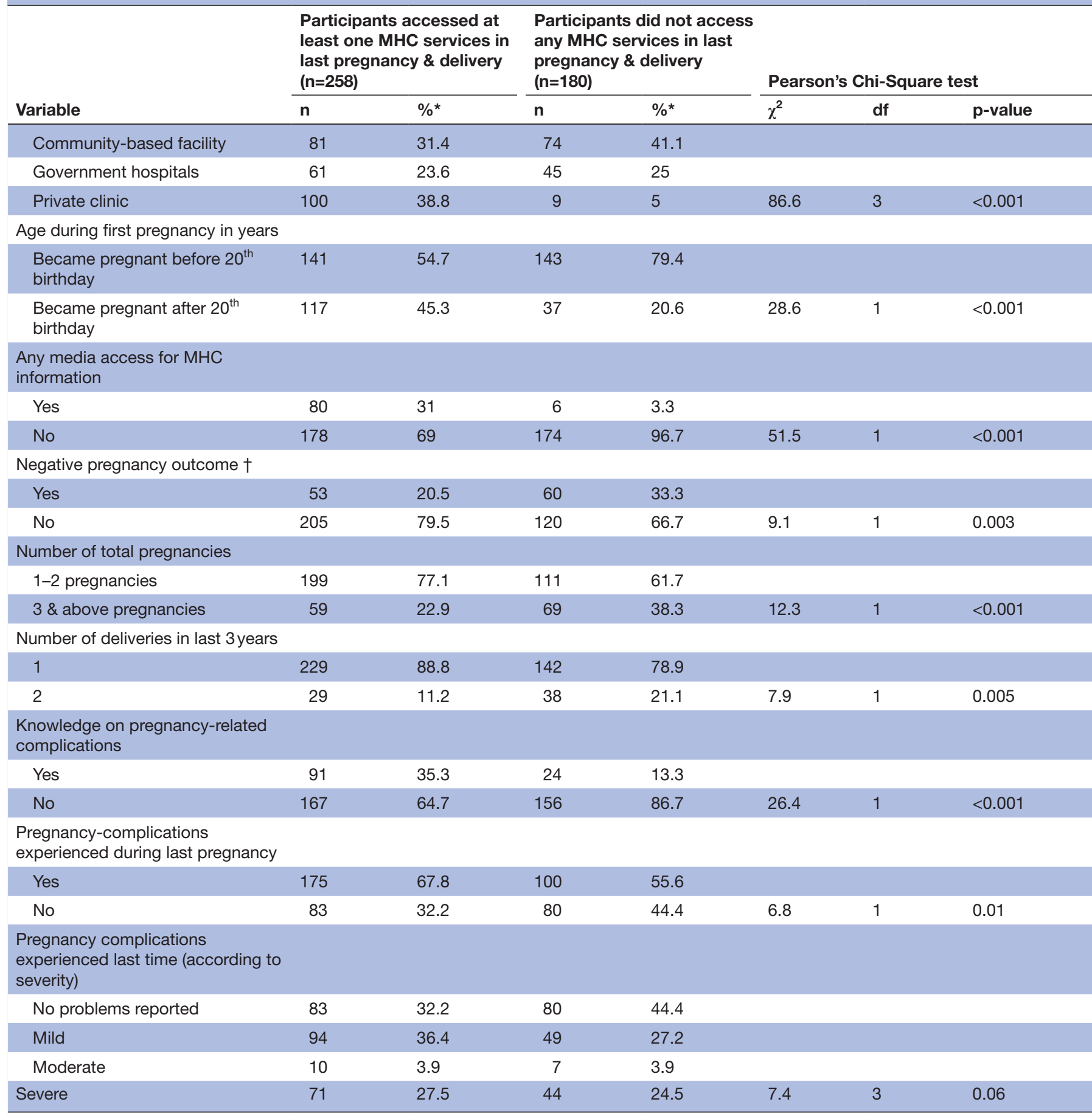

${ }^{*}$ Column percentages.

†Negative pregnancy outcomes=pregnancy that resulted in miscarriage/abortion/stillbirth/live birth but the child died $<1$ month .

BDT, Bangladeshi Taka.

ANC service access only increased by $4 \% .^{6}$ This current study collected data in paras without consideration of any intervention programme. Findings reported here provide important information on Indigenous women's access to MHC services not previously obtained for this population that could inform interventions and influence policy.

Sociodemographic characteristics of participants of this current study indicated that level of school attendance was lower among the Indigenous population (35.8\%) than the national percentage of literacy $(66 \%)$ among ever-married women aged $15-49 .{ }^{29}$ Higher level of school attendance, higher household income and lack of knowledge regarding existing nearby facilities were major factors influencing MHC service access among Indigenous women in the CHT, similar to studies in China, Vietnam and India. ${ }^{22} 2456$ A majority of Indigenous 
Table 2 Univariate and multivariable logistic regression models for identifying factors associated with access to maternal healthcare services (MHC) among Indigenous women in Chittagong Hill Tracts, Bangladesh, after adjusting for clustering by para

\begin{tabular}{|c|c|c|c|c|c|c|c|}
\hline \multirow[b]{2}{*}{ Variables } & \multirow[b]{2}{*}{$n(\%)$} & \multicolumn{3}{|c|}{ Univariate analysis } & \multicolumn{3}{|c|}{ Multivariable logistic regression } \\
\hline & & OR & $\begin{array}{l}95 \% \mathrm{Cl} \text { for } \\
\text { OR }\end{array}$ & $P$ value & Adjusted OR & $\begin{array}{l}95 \% \mathrm{Cl} \text { for } \\
\text { AOR }\end{array}$ & $P$ value \\
\hline \multicolumn{8}{|l|}{ Place of residence (subdistrict) } \\
\hline Matiranga & $325(74.2)$ & Ref & & & & & \\
\hline Khagrachhari Sadar & $113(25.8)$ & 4.2 & 2.5 to 7.1 & $<0.001$ & 2.4 & 0.90 to 7.0 & 0.10 \\
\hline \multicolumn{8}{|l|}{ Ethnicity } \\
\hline Chakma & $220(50.2)$ & Ref & & & Ref & & \\
\hline Marma & $100(22.8)$ & 1.6 & 1.0 to 2.8 & 0.05 & 0.8 & 0.32 to 2.0 & 0.70 \\
\hline Tripura & $118(27.0)$ & 0.50 & 0.34 to 0.84 & 0.006 & 0.5 & 0.25 to 1.3 & 0.20 \\
\hline \multicolumn{8}{|l|}{ Age } \\
\hline Young (15-29) & $328(74.9)$ & Ref & & & Ref & & \\
\hline Adult (30 and above) & $110(25.1)$ & 1.9 & 1.2 to 3.0 & 0.007 & 1.7 & 0.90 to 3.5 & 0.10 \\
\hline \multicolumn{8}{|l|}{ School attendance } \\
\hline Did not attend-Junior & $281(64.2)$ & Ref & & & Ref & & \\
\hline Secondary and above & $135(35.8)$ & 7.9 & 4.7 to 13.1 & $<0.001$ & 2.4 & 1.2 to 4.9 & 0.01 \\
\hline \multicolumn{8}{|l|}{ Household income } \\
\hline $4000-9000$ & $198(45.2)$ & Ref & & & Ref & & \\
\hline $10000-19000$ & $111(25.3)$ & 2.1 & 1.3 to 3.3 & 0.002 & 1.1 & 0.61 to 2.1 & 0.24 \\
\hline 20000 and above & $129(29.5)$ & 8.2 & 4.7 to 14.4 & $<0.001$ & 2.0 & 0.90 to 4.4 & 0.11 \\
\hline \multicolumn{8}{|l|}{$\begin{array}{l}\text { Knowledge of nearest health } \\
\text { facilities }\end{array}$} \\
\hline No & $68(15.5)$ & Ref & & & Ref & & \\
\hline Yes & $370(84.5)$ & 6.1 & 3.4 to 11.1 & $<0.001$ & 3.8 & 1.8 to 7.8 & $<0.001$ \\
\hline \multicolumn{8}{|l|}{$\begin{array}{l}\text { Access to media access for } \\
\text { MHC information }\end{array}$} \\
\hline No & $352(80.4)$ & Ref & & & Ref & & \\
\hline Yes & $86(19.6)$ & 13.0 & 5.5 to 30.7 & $<0.001$ & 2.3 & 0.76 to 7.2 & 0.14 \\
\hline \multicolumn{8}{|l|}{$\begin{array}{l}\text { Knowledge on pregnancy- } \\
\text { related complications }\end{array}$} \\
\hline No & $323(73.7)$ & Ref & & & Ref & & \\
\hline Yes & $115(26.3)$ & 3.5 & 2.1 to 5.8 & $<0.001$ & 3.0 & 1.5 to 5.8 & 0.002 \\
\hline \multicolumn{8}{|l|}{ Number of total pregnancies } \\
\hline 1-2 pregnancies & $310(70.8)$ & Ref & & & Ref & & \\
\hline 3 and above pregnancies & $128(29.2)$ & 0.50 & 0.31 to 0.72 & 0.001 & 0.54 & 0.30 to 1.0 & 0.05 \\
\hline
\end{tabular}

AOR, adjusted Odds Ratio; Cl, Confidence Interval; OR, Odds Ratio.

women in this survey were involved in income-generating activities outside the home including daily labour; however, occupation was not an independent factor for accessing MHC services. In theory, working women are expected to have more freedom and knowledge about pregnancy and delivery, and therefore, are more likely to access healthcare facilities. ${ }^{36}$ While Indigenous women in Khagrachhari were involved in income-generation activities, most were working as daily labourers and attended school up to primary level. Similar findings from China revealed that Indigenous women's priorities are more related to income and time rather than their pregnancy which they perceived as low risk. ${ }^{22}$

Ethnicity was a significant factor in accessing MHC services, with Chakma women accessing services at a higher rate than Marma and Tripura women (52\%, 28\% and $20 \%$, respectively) indicating that not all Indigenous groups enjoy equal and equitable health rights in accessing MHC services. Of the services, ANC services were accessed at the highest rate among the Indigenous 
women, with lower rates for facility delivery and even lower for PNC services.

Exposure to mass media was a main reason for not accessing MHC facilities among Indigenous women in lower and middle-income countries. The cross-sectional study on Mru Indigenous community, Bangladesh, also reported that exposure to mass media positively influenced women's access to ANC services. ${ }^{19}$ Although Indigenous women of Khagrachhari district had access to different electronic media, including mobile phones, using these media to access MHC services was very limited. This is an important finding for developing mobile health initiatives in rural and remote areas of Bangladesh. ${ }^{37}$

Of Indigenous women with their first pregnancy before age 20,79\% did not access any MHC services during their last pregnancy or delivery. Similar to many Indigenous groups around the world, adolescent fertility and unintended pregnancies are worryingly higher among Indigenous women in the CHT compared with the national average, requiring extra attention. ${ }^{38}{ }^{39}$ The adolescent pregnancy rate in this study is double the national percentage $(65 \%$ vs $31 \%$ ) with fewer adolescent Indigenous women accessing MHC services (16\%) compared with the national rate $(80 \%) .{ }^{29} 3940$

Evidence from the 2004-2014 nationwide survey revealed the pooled rate of stillbirth was 28 per 1000 total births in Bangladesh. ${ }^{41}$ Although negative pregnancy outcomes in this study were not statistically significantly higher among Indigenous women compared with the national average, 26\% ( $\mathrm{n}=113)$ of CHT Indigenous women experienced a negative pregnancy outcome, and of this only $21 \%$ accessed an MHC service during their last pregnancy or delivery. Miscarriage was voluntarily reported by 45 participants $(10.3 \%$, see online supplementary table 2) and was included as a negative pregnancy outcome because gender-based inequalities contribute towards reproductive health problems including miscarriages. ${ }^{42}$ According to a profile report in Bangladesh, $11 \%$ of all pregnancies resulted in termination of which $7 \%$ were spontaneous miscarriages. ${ }^{43}$ Accurate assessment of miscarriage is challenging because of the associated stigma; however, this survey was developed following the Bangladesh Demographic and Health Survey where data on miscarriage was collected. ${ }^{29}$

There was a knowledge gap among Indigenous women regarding pregnancy-related health problems, as three-quarters of participants experienced mild-to-severe health problems in their last pregnancies but were not aware of these potential problems. Quality MHC services provision that target this group of women may reduce negative pregnancy outcomes. ${ }^{445}$

Previous studies reveal that Indigenous peoples perceived pregnancy and delivery as 'natural events', and would only visit health facilities if the situation becomes out of control. ${ }^{21} 232526$ CHT Indigenous women with knowledge of pregnancy-related complications were more likely to access MHC services during pregnancy and delivery. Two studies from India reported Indigenous women who delivered more than three children were less likely to attend ANC services. ${ }^{24}{ }^{46}$ In the current study, Indigenous women with more than three children had reduced odds of accessing MHC services.

Pregnant women receive health education regarding pregnancy and delivery including pregnancy-related complications during their ANC check. ${ }^{1}$ ANC service utilisation is considered an indicator of the likelihood for accessing facility delivery services or seeking help from a skilled birth attendant at childbirth, as well as increasing awareness of PNC services. ${ }^{47}{ }^{48}$ Evidence suggests that Indigenous pregnant women who accessed ANC services but did not access delivery or PNC services may not have been adequately encouraged, well-treated or supported by the health system; or that MHC services were not culturally appropriate, causing dissatisfaction among Indigenous communities. ${ }^{48} 49$ In a multicountry (Guatemala, Mexico and Panama) analysis, attending one or more ANC checks led to women accessing further MHC services. However, in this study, accessing ANC services did not appear to influence accessing delivery and PNC services by the Indigenous women, and the majority were unaware of pregnancy-related complications. These healthcare access inequities indicate that further research is needed to identify gaps in the MHC facility services for Indigenous women.

Most Indigenous women in this study preferred receiving free healthcare services from a known Indigenous healthcare provider; however, a limited number were aware of their nearest primary healthcare facilities. This indicates a gap between service providers and service receivers contributing to health inequality and inequity. Indigenous people express disinterest in using available healthcare services if service providers are unresponsive towards their needs, show discriminatory behaviour or are unfriendly. Evidence-based research is required in the context of Indigenous women in the CHT to identify gaps in equal and equitable health rights.

This study was conducted in the three dominant ethnic communities of the Khagrachhari district, the major ethnic groups in the two other hill districts sharing similar sociocultural status. ${ }^{12}$ Data collection was designed to reduce bias and increase generalisability by attempting to recruit all eligible Indigenous women in the para. ${ }^{50}$ Findings provide a reasonable estimate of prevalence for accessing MHC by Indigenous women generalisable within these CHT communities providing useful insights for optimising existing MHC services for Indigenous communities through addressing gaps within the system. Not using Indigenous languages for the survey may have led to some communication barriers as the questionnaire did not use Indigenous dialectic terms for pregnancy and delivery which may have restricted opportunities for transferring knowledge to participants. ${ }^{51}$ As a cross-sectional study, measurements from the population were obtained at a single time point, precluding causal inference. However, observational study designs are effective in planning for healthcare services. ${ }^{52}$ 


\section{CONCLUSION}

Suboptimal access to MHC services among Indigenous women in the CHT, Bangladesh, indicated by an estimated prevalence of $59 \%$ is associated with sociodemographic characteristics such as school attendance, household income and media access. Indigenous women had limited knowledge of nearby health facilities and pregnancy-related complications. Considering the importance of accessing MHC services to improve health outcomes for all, it is critical to address these gaps in access. Culturally, appropriate interventions that use health facility and community-based educational approaches are needed to reach Indigenous women in the CHT. Differences within ethnic groups should be taken into account while designing interventions to make access more inclusive. Underlying reasons for Indigenous women not accessing further MHC services after accessing ANC services need to be explored. Effective measures should be taken immediately to improve access to facility delivery and PNC services. Training Indigenous health workers to promote maternal healthcare education within communities would be an effective approach and would help ensure sustainability of programme.

\section{Author affiliations}

${ }^{1}$ School of Medicine and Public Health, University of Newcastle, Newcastle, New South Wales, Australia

${ }^{2}$ Priority Research Centre for Generational Health and Ageing, University of Newcastle, Callaghan, New South Wales, Australia

${ }^{3}$ Hunter Medical Research Institute, New Lambton Heights, New South Wales, Australia

${ }^{4}$ Department of Anthropology, Jagannath University, Dhaka, Bangladesh

${ }^{5}$ Centre for Resources Health and Safety, Newcastle Institute of Energy and Resources, Shortland, New South Wales, Australia

${ }^{6}$ School of Humanities and Social Science, University of Newcastle, Newcastle, New South Wales, Australia

${ }^{7}$ School of Nursing and Midwifery, Faculty of Health and Medicine, University of Newcastle, Newcastle, New South Wales, Australia

Twitter Shahinoor Akter @akter_shahinoor

Acknowledgements The authors are thankful to all the Indigenous women who participated and shared their information for this research, and local community leaders for their invaluable support. They also thank the field workers involved in the data collection. Finally, they thank the University of Newcastle, Australia, for funding the scholarship and Jagannath University, Bangladesh, for its support to conduct this research.

Contributors SA conceived and designed the study and undertook data collection under the guidance of KJI, KD and JLR. SA and KJl analysed and interpreted the data. SA wrote the draft of the manuscript. KJI, KD and JLR critically edited the manuscript and supervised the study. All authors read and approved the final manuscript.

Funding This research was supported by an Australian Government Research Training Program Scholarship and an International Postgraduate Research Scholarship from the University of Newcastle.

Map disclaimer The depiction of boundaries on the map(s) in this article does not imply the expression of any opinion whatsoever on the part of BMJ (or any member of its group) concerning the legal status of any country, territory, jurisdiction or area or of its authorities. The map(s) are provided without any warranty of any kind, either express or implied.

Competing interests None declared.

Patient consent for publication Not required.
Ethics approval Ethical approvals were obtained from the Human Research Ethics Committee of the University of Newcastle, Australia (H-2017-0204) and Department of Anthropology at Jagannath University, Bangladesh.

Provenance and peer review Not commissioned; externally peer reviewed.

Data availability statement Data are available upon reasonable request. Nonidentifiable data may be shared with other parties to encourage scientific scrutiny and to contribute to further research and public knowledge. Data are available by contacting the first author and with permission from all co-authors; re-use of deidentifiable data may be permitted on agreement of a statistical analysis plan.

Open access This is an open access article distributed in accordance with the Creative Commons Attribution Non Commercial (CC BY-NC 4.0) license, which permits others to distribute, remix, adapt, build upon this work non-commercially, and license their derivative works on different terms, provided the original work is properly cited, appropriate credit is given, any changes made indicated, and the use is non-commercial. See: http://creativecommons.org/licenses/by-nc/4.0/.

\section{ORCID iDs}

Shahinoor Akter http://orcid.org/0000-0002-5236-3597

Kerry Jill Inder http://orcid.org/0000-0003-4412-0322

\section{REFERENCES}

1 Bhowmik J, Biswas RK, Woldegiorgis M. Antenatal care and skilled birth attendance in Bangladesh are influenced by female education and family affordability: BDHS 2014. Public Health 2019;170:113-21.

2 Brizuela V, Tunçalp Özge. Global initiatives in maternal and newborn health. Obstet Med 2017;10:21-5

3 Alkema L, Chou D, Hogan D, et al. Global, regional, and national levels and trends in maternal mortality between 1990 and 2015, with scenario-based projections to 2030: a systematic analysis by the un maternal mortality estimation Inter-Agency group. The Lancet 2016;387:462-74.

4 Kamal N, Curtis S, Hasan MS, et al. Trends in equity in use of maternal health services in urban and rural Bangladesh. Int $J$ Equity Health 2016;15:27.

5 World Health Organization. SDG 3: ensure healthy lives and promote wellbeing for all at all ages: World Health organization, 2019. Available: https://www.who.int/sdg/targets/en/ [Accessed $3 \mathrm{Apr}$ 2019].

6 Badiuzzaman M, Murshed SM, Rieger M. Improving maternal health care in a post conflict setting: evidence from Chittagong Hill tracts of Bangladesh. J Dev Stud 2018;36:1-17.

7 National Institute of Population Research and Training (NIPORT), International Centre for Diarrhoeal Disease Research Bangladesh (icddr b, MEASURE Evaluation. Bangladesh maternal mortality and health care survey (BMMS) 2016: preliminary report. Dhaka, Bangladesh and Chapel Hill, NC, USA; 2017.

8 World Health Organization. Success factors for women's and children's health: Bangladesh 2015.

9 Pulok MH, Sabah MN-US, Uddin J, et al. Progress in utilization of antenatal and delivery care services in Bangladesh: where does the equity gap lie? BMC pregnancy and childbirth 2015.

10 International Work Group for Indigenous Affairs. State of Indigenous women and girls in Bangladesh: issues and concerns at a glance, 2016. Available: http://www.iwgia.org/iwgia_files_publications_files/ 0753_Briefing_Paper_State_of_indigenous_omen_and_girls_in_ Bangladesh_October_2016.pdf

11 Roy P, Promila M. Quest for security, equality, equity and integration: locus of Indigenous women in Bangladesh. Thailand Asia Indigenous peoples PACT (AIPP) and Kapaeeng Foundation; 2014.

12 Barkat A, Halim S, Poddar A. Socio-Economic baseline survey of Chittagong Hill tracts. Dhaka; 2009.

13 Uddin A. Dynamics of strategies for survival of the Indigenous people in southeastern Bangladesh. Ethnopolitics 2016;15:319-38.

14 Van Schendel W, Mey W, Dewan AK. The Chittagong Hill tracts: living in a borderland: white Lotus Bangkok 2000.

15 Kamal SMM, Hassan CH. Socioeconomic correlates of contraceptive use among the ethnic tribal women of Bangladesh: does sex preference matter? J Family Reprod Health 2013;7:73-86.

16 Lennox C. Addressing health inequalities in the post-2015 development framework. State of the world's minorities and indigenous peoples 2013:13-25.

17 UNICEF. Chittagong Hill tracts: UNICEF, 2015. Available: http://www. unicef.org/bangladesh/CHT.pdf [Accessed 27 Sep 2018].

18 Tuhin M, Ameen A. Health discourse in Chittagong Hill tracts in Bangladesh UiT NorgesArktiske Universitet; 2015. 
19 Islam RM. Utilization of maternal health care services among Indigenous women in Bangladesh: a study on the Mru tribe. Women Health 2017;57:108-18.

20 Islam MR, Odland JO. Determinants of antenatal and postnatal care visits among Indigenous people in Bangladesh: a study of the Mru community. Rural Remote Health 2011;11:1672.

21 Ibáñez-Cuevas M, Heredia-Pi IB, Meneses-Navarro S, et al. Labor and delivery service use: Indigenous women's preference and the health sector response in the Chiapas highlands of Mexico. Int $J$ Equity Health 2015;14:156.

22 Harris A, Zhou Y, Liao H, et al. Challenges to maternal health care utilization among ethnic minority women in a resource-poor region of Sichuan Province, China. Health Policy Plan 2010;25:311-8.

23 Ruiz MJ, van Dijk MG, Berdichevsky K, et al. Barriers to the use of maternity waiting homes in Indigenous regions of Guatemala: a study of users' and community members' perceptions. Cult Health Sex 2013;15:205-18.

24 Varma GR, Kusuma YS, Babu BV. Antenatal care service utilization in tribal and rural areas in a South Indian district: an evaluation through mixed methods approach. J Egypt Public Health Assoc 2011;86:11-15.

25 White J, Oosterhoff P, Huong NT. Deconstructing 'barriers' to access: minority ethnic women and medicalised maternal health services in Vietnam. Glob Public Health 2012;7:869-81.

26 Akter S, Davies K, Rich JL, et al. Indigenous women's access to maternal healthcare services in lower- and middle-income countries: a systematic integrative review. Int J Public Health 2019;64:343-53.

27 Bangladesh Bureau of Statistics. Bangladesh population and housing census 2011: community report: Khagrachhari. Bangladesh; 2015.

28 Bangladesh Bureau of Statistics. District statistics 2011 Khagrachhari: Bangladesh Bureau of Statistics (BBS); 2013.

29 National Institute of Population Research and Training (NIPORT), Mitra and Associates, ICF International. Bangladesh demographic and health survey. Dhaka, Bangladesh, and Rockville, Maryland, USA National Institute of Population Research and Training (NIPORT); 2014.

30 Yohannes B, Tarekegn M, Paulos W. Mothers' utilization of antenatal care and their satisfaction with delivery services in selected public health facilities of wolaita zone, southern Ethiopia. International Journal of Scientific Technology Research 2013;2:74-85.

31 Harris PA, Taylor R, Thielke R, et al. Research electronic data capture (REDCap)--a metadata-driven methodology and workflow process for providing translational research informatics support. J Biomed Inform 2009;42:377-81.

32 Hossain DM. Socio-Economic Situation of the Indigenous People in the Chittagong Hill Tracts (CHT) of Bangladesh. Middle East Journal of Business 2013;8:22-30.

33 Ministry of Health and Family Welfare (MoHFW). Bangladesh population policy 2012 Government of the People's Republic of Bangladesh; 2012.

34 World Health Organization, UNICEF. Managing complications in pregnancy and childbirth: a guide for midwives and doctors - 2nd ed, 2017. Available: https://apps.who.int/iris/bitstream/handle/10665/ 255760/9789241565493-eng.pdf [Accessed 1 Nov 2018].

35 Stephens C, Porter J, Nettleton C, et al. Disappearing, displaced, and undervalued: a call to action for Indigenous health worldwide. The Lancet 2006;367:2019-28.
36 Desai S, Jain D. Maternal employment and changes in family dynamics: the social context of women's work in rural South India. Popul Dev Rev 1994;20:115-36.

37 Khatun F, Heywood AE, Ray PK, et al. Community readiness for adopting $\mathrm{mHealth}$ in rural Bangladesh: a qualitative exploration. Int $J$ Med Inform 2016;93:49-56.

38 Valeggia CR, Snodgrass JJ. Health of Indigenous peoples. Annu Rev Anthropol 2015;44:117-35.

39 World Health Organisation. Adolescent pregnancy, 2018. Available: http://www.who.int/news-room/fact-sheets/detail/adolescentpregnancy [Accessed 23 Feb 2018].

40 Shahabuddin A, Nöstlinger C, Delvaux T, et al. Exploring maternal health care-seeking behavior of married adolescent girls in Bangladesh: a social-ecological approach. PLoS One 2017;12:e0169109.

41 Abir T, Agho KE, Ogbo FA, et al. Predictors of stillbirths in Bangladesh: evidence from the 2004-2014 nation-wide household surveys. Glob Health Action 2017;10:1410048.

42 Silverman JG, Gupta J, Decker MR, et al. Intimate partner violence and unwanted pregnancy, miscarriage, induced abortion, and stillbirth among a national sample of Bangladeshi women. BJOG 2007; 114:1246-52.

43 Huda FA, Chowdhuri S, Robertson Y. Understanding unintended pregnancy in Bangladesh: country profile report. Dhaka, Bangladesh Centre for Reproductive Health, icddr b; 2013

44 Chaibva BV, Olorunju S, Nyadundu S, et al. Adverse pregnancy outcomes, 'stillbirths and early neonatal deaths' in Mutare district, Zimbabwe (2014): a descriptive study. BMC Pregnancy Childbirth 2019;19:86.

45 Zhu J, Liang J, Mu Y, et al. Sociodemographic and obstetric characteristics of stillbirths in China: a census of nearly 4 million health facility births between 2012 and 2014. Lancet Glob Health 2016;4:e109-18.

46 Adhikari T, Sahu D, Nair S, et al. Factors associated with utilization of antenatal care services among tribal women: a study of selected states. Indian J Med Res 2016;144:58-66.

47 Rockers PC, Wilson ML, Mbaruku G, et al. Source of antenatal care influences facility delivery in rural Tanzania: a population-based study. Matern Child Health J 2009;13:879-85.

48 Dansereau E, Hernandez B, Mokdad AH. Antenatal care among poor and Indigenous women in Central America and Mexico: A cross-country study of access, utilization, and barriers. In: Schwartz DA, ed. Maternal death and pregnancy-related morbidity among Indigenous women of Mexico and central America: an anthropological, epidemiological, and biomedical approach. USA Springer, 2018: 133-44.

49 Colombara DV, Hernández B, Schaefer A, et al. Institutional delivery and satisfaction among Indigenous and poor women in Guatemala, Mexico, and Panama. PLoS One 2016;11:e0154388.

50 Sedgwick P. Bias in observational study designs: cross sectional studies. BMJ 2015;350:h1286.

51 Amano T, González-Varo JP, Sutherland WJ. Languages are still a major barrier to global science. PLoS Biol 2016;14:e2000933.

52 Sedgwick P. Cross sectional studies: advantages and disadvantages. BMJ 2014;348:g2276. 